\title{
POTENSI PENGEMBANGAN WISATA SPIRITUAL DI KAMPUNG BUDAYA SINDANGBARANG, BOGOR
}

\author{
Seruni Dinitri \\ Sekolah Tinggi Pariwisata Bogor, seruni.dinithree@gmail.com
}

\begin{abstract}
:
Kampung Budaya Sindangbarang is one of tourism destination in Bogor Regency that has a beautiful landscape, high cultural value, and the discovery of historical sites around it. The purpose of this research is to find out the potency to develop spiritual tourism in Sindangbarang Cultural Village. This research uses a descriptive method with quantitave approach. Primary data were obtained through interview with the management of Sindangbarang Cultural Village, questionnaire distribution and also direct observation. For secondary data obtained through data from the Bogor Regency Tourism Office, the Central Statistics Agency, documentations of Sindangbarang Cultural Village, other relevant institutions, journals and other supporting books. Variables used to see the potency to develop spiritual tourism using Spiritual Element theory (Pechlaner, 2010 in Conrady, 2011) with dimensions of attraction, places and motives. Based on the results of the analysis found that elements of spiritual tourism in the form of attraction, places and motives can become the strength of Sindangbarang Cultural Village in developing spiritual tourism.
\end{abstract}

Keyword: Potency of Development, Spiritual Tourism, Kampung Budaya Sindangbarang

\section{LATAR BELAKANG}

Wisata spiritual merupakan trend baru di dunia pariwisata yang kecenderungannya terus meningkat. Jenis wisata ini sangat potensial untuk dikembangkan dan cukup berkualitas, karena dalam praktiknya jenis wisata ini sangat menghargai tradisi budaya lokal, mencintai alam dan lingkungan, serta sebagian besar wisatawannya berasal dari kalangan yang berpendidikan. Berdasarkan Herdina (2012) dijelaskan bahwa wisata spiritual merupakan salah satu alternatif wisata yang bisa dilakukan oleh masyarakat urban, untuk memulihkan kondisi fisik dan jiwa karena padatnya aktifitas yang padat sehari-harinya. The World Tourism Organization (UNWTO) dalam situs semarang.bisnis.com (2017) menyebut Indonesia memiliki potensi mengembangkan wisata spiritual. Mereka menilai Indonesia memiliki keberagamaan situs keagamaan hasil interaksi berbagai sistem kebudayaan kepercayaan pada masa lalu.

Kampung Budaya Sindangbarang merupakan salah satu destinasi pariwisata di Kabupaten Bogor yang berada di Desa Pasir Eurih, Kecamatan Tamansari. Berdiri sejak Tahun 2007, Kampung Budaya Sindangbarang dibentuk dilatarbelakangi oleh upaya pengembangan dan pelestarian kebudayaan Sunda yang hampir punah sehingga tidak hilang dan bisa menjadi warisan generasi mendatang, dan juga nilai sejarah yang terdapat diwilayah tersebut. 


\section{National Conference of Creative Industry: \\ Sustainable Tourism Industry for Economic Development}

Universitas Bunda Mulia, Jakarta, 5-6 September 2018 e-ISSN No: 2622-7436

Diawali dari sejarah kawasan Sindangbarang yang diceritakan secara turun temurun dalam bentuk Pantun Bogor dan juga Babad Pakuan, ditemukannya berbagai peninggalan- peninggalan bersejarah seperti menhir, dolmen, punden berundak, sumur Jalatunda, taman Sri Bagenda, makam leluhur Sindangbarang, dan lain-lain yang bertebaran di sekitar daerah tersebut.

Dalam Munandar (2006) berdasarkan laporan hasil penelitian awal dalam Situs Sindangbarang Bukti Kegiatan Keagamaan Masyarakat Kerajaan Sunda (Abar 13-15 M) berargumen bahwa peninggalan purbakala yang ditemukan di wilayah Kampung Sindangbarang berasal dari masyarakat Sunda Kuna disekitar abad ke-15M hingga keruntuhannya. Data yang digunakan diketahui berdasarkan data arkeologis dan sumber tertulis.

\section{PERMASALAHAN}

Kampung Budaya Sindangbarang sendiri mempunyai nilai sejarah yang cukup kental dan dapat dijadikan potensi untuk mengembangkan wisata spiritual dengan mengemas dari nilai sejarah dan berbagai situs yang ditemukan, ditambah dengan kebudayaan yang cukup kental, suasana alam yang cukup tenang, juga tidak begitu jauh dari perkotaan terutama dari Ibukota Negara Indonesia. Berdasarkan data jumlah pengunjung ke Kampung Budaya Sindangbarang selama hampir 10 tahun (2008-2016) didapatkan informasi bahwa semenjak Tahun 2014 jumlah pengunjung cenderung menurun.

Berdasarkan hasil wawancara dengan Kokolot Kampung Budaya Sindangbarang, Abah Ukat, ditemukan bahwa terdapat pengunjung yang selain ingin mengenal budaya Sindangbarang, juga ingin melakukan meditasi dan melakukan trecking ke beberapa situs sejarah. Namun sampai dengan saat ini Kampung Budaya Sindangbarang baru memfokuskan diri para pengembangan wisata budaya dan sejarah. Oleh karena itu maka perlu dilakukan analisis untuk melihat potensi pengembangan wisata spiritual sebagai added value dari pengembangan wisata budaya dan sejarah yang sudah diterapkan oleh Kampung Budaya Sindangbarang selama hampir 10 tahun kebelakang. Langkah selanjutnya untuk pengembangan wisata spiritual di Kampung Budaya Sindangbarang adalah dalam bentuk pertanyaan: bagaimana potensi pengembangan wisata spiritual di Kampung Budaya Sindangbarang?

\section{TINJAUAN PUSTAKA}

\section{a. Potensi Wisata}

Menurut Pendit (1999) dalam buku Ilmu Pariwisata bahwa potensi wisata adalah segala sesuatu yang dapat dikembangkan menjadi daya tarik wisata. Potensi wisata tersebut dapat dibagi menjadi 3 bagian, yaitu:

(1). Potensi budaya adalah potensi yang tumbuh dan berkembang di masyarakat baik itu adat istiadat, mata pencaharian, kesenian, dan budaya.

(2). Potensi alamiah adalah potensi yang ada di masyarakat berupa potensi fisik dan geografi seperti alam.

(3). Potensi manusia adalah manusia juga memiliki potensi yang dapat digunakan sebagai daya tarik wisata, lewat pementasan tarian/pementasan seni budaya suatu daerah. 


\section{National Conference of Creative Industry: \\ Sustainable Tourism Industry for Economic Development}

Universitas Bunda Mulia, Jakarta, 5-6 September 2018 e-ISSN No: 2622-7436

Potensi wisata adalah segala sesuatu yang dimiliki oleh daerah tujuan wisata, dan merupakan daya tarik agar orang-orang mau datang berkunjung ke tempat terebut (Mariotti dalam Yoeti 1996:160-162). Sedangkan menurut Sukardi (1998:67), potensi wisata adalah segala sesuatu yang dimiliki oleh suatu daerah untuk daya tarik wisata dan berguna untuk mengembangkan industri pariwisata di daerah tersebut.

\section{b. Wisata Spiritual}

Munculnya istilah pariwisata spiritual atau wisata spiritual tidak bisa terlepas dengan adanya Gerakan Zaman Baru atau The New Age Movement. The New Age adalah potret zaman yang memadukan rasionalisme Barat dengan mistik spiritual Timur. Ciri utama dari zaman ini adalah penolakan terhadap agama formal, karena dipandang cenderung mengekang kebebasan individu. Kesejukan spiritual bisa diselami dan dinikmati dengan menembus batas agama. Esensi semua agama diyakini sama, dan seluruh realitas dilihat sebagai pancaran Tuhan. Aktifitas yang dilakukan The New Agers adalah wisata spiritual lintas agama (Sukidi, 2001).

Pada beberapa filosofi spiritual, tidak berfokus pada Tuhan dalam satu atau beberapa agama tertentu, namun lebih kepada menyalurkan pengabdian ke bumi dan alam semesta. Sistem kepercayaan berbasis alam memusatkan perhatian pada manusia sebagai bagian dari alam, tidak terpisah darinya. Dari sudut pandang ini, manusia tidak memiliki kekuasaan atas bumi, dan juga tidak harus mengendalikannya. Sebaliknya, mereka hanyalah satu bagian dari sistem yang lebih besar dimana semua hal di bumi, termasuk bumi yang berinteraksi, memiliki semangat, hidup, dan mampu merasakannya (Timothy, 2006:140)

Smith \& Kelly (2006) memberikan gambaran bahwa yang dimaksud wisata spiritual adalah segala jenis aktifitas dan atau perlakuan berwisata yang bertujuan untuk mengembangkan, merawat dan meningkatkan badan, pikiran dan jiwa.

Berdasarkan Berkemann, wisata spiritual pada umumnya adalah segala bentuk wisata, yang termasuk perjalanan spiritual dan fisik (Barkemann, 2006). Interaksi dari tubuh dan pikiran juga ditekankan oleh Brämer, yang memahami spiritualitas sebagaipenyatuan kepala, hati dan tubuh, yang terutama bisa dicapai dengan cara gerakan fisik di alam (Brämer, 2009). Freyer (1996) dan Steinecke (2007) di sisi lain melihat motivasi wisata spiritual atau religious sebagai bagian dari pariwisata yang berorientasi budaya.

Sedangkan Pitana (2012) menyatakan bahwa sebenarnya wisata spiritual telah hadir di bumi sejak berabad-abad lalu. Wisatawan spiritual berwisata ke suatu tempat untuk mencari kedamaian dan keharmonisan (peace and harmony), dan mereka kebanyakan orang yang berpendidikan, peduli pada budaya, peduli pada alam dan lingkungan, dan tidak mengganggu siapapun.

Berdasarkan pendapat beberapa sumber diatas, Penulis cenderung mengikuti pandangan bahwa wisata spiritual adalah wisata untuk mencari pengalaman spiritual yang tidak memandang satu agama tertentu, namun lebih berfokus pada mencari kedamaian dan keharmonisan diri.

\section{c. Pengembangan pariwisata}

Pengembangan pariwisata menurut Swarbrooke (2002) merupakan suatu rangkaian upaya untuk mewujudkan keterpaduan dalam penggunaan berbagai sumber daya pariwisata 


\section{National Conference of Creative Industry: \\ Sustainable Tourism Industry for Economic Development}

Universitas Bunda Mulia, Jakarta, 5-6 September 2018

e-ISSN No: 2622-7436

dalam mengintegrasikan segala bentuk aspek diluar pariwisata yang berkaitan secara langsung maupun tidak langsung akan kelangsungan pengembangan pariwisata.

Di bidang atraksi wisata ada beberapa jenis utama pengembangan:

(1). Atraksi dibangun sepenuhnya di tempat yang sebelumnya belum pernah dijadikan obyek wisata, misalnya Disneyland Paris

(2). Objek tujuan yang dibangun dikembangkan dari tempat yang sebelumnya sudah digunakan sebagai obyek wisata, seperti Legoland, dibangun di atasTaman Safari Windsor, Inggris.

(3). Pengembangan dilakukan untuk menarik lebih banyak pengunjung dan membiarkan daya tarik untuk membentuk target market baru.

(4). Pengembangan baru dilakukan yang digunakan untuk memperbaiki fasilitas atraksi dan untuk meningkatkan pengeluaran sekunder dari wisatawan. Contoh: gerai ritel baru dan catering bertema di banyak museum.

(5). Penciptaan event-event baru atau pembuatan event yang berpindah tempat dari waktu ke waktu. Contoh: Olimpiade

Agen pengembangan meliputi public sector (Pemerintah, Pemerintah Daerah), Private Sector (organisasi transnasional, pengusaha, pengembang dll), Voluntary Sector (LSM, dll).

Ridwan (2012:47) menyatakan pendapatnya tentang kebijakan perencanaan pengembangan pariwisata sebagai berikut:

"Perencanaan pengembangan pariwisata pada dasarnya adalah untuk mencari titik temu antara penawaran dengan permintaan. Oleh karena itu dalam melakukan perencanaan pengembangan pariwisata seharusnya terlebih dahulu mengidentifikasi produk wisatanya (penawaran) yang ada di daerah tujuan wisata dan pasar wisatawan (permintaan), baik aktual maupun potential kemudian dilakukan suatu analisis terhadap kedua aspek tersebut tercapai”

Tahapan pengembangan juga merupakan tahapan siklus evolusi yang terjadi dalam pembangunan pariwisata, sejak suatu daerah tujuan wisata baru ditemukan (discovery), kemudian berkembang dan pada akhirnya terjadi penurunan (decline). Oleh karena itu siklus hidup pariwisata mengacu pada pendapat Butler (1980) yang dikutip oleh Cooper dan Jackson (1997) tentang Tourism Life Cycle dengan tahapan sebagai berikut:

(1). Tahap exploration, yang berkaitan dengan discovery yaitu tempat sebagai potensi wisata baru ditemukan baik oleh wisatawan, pelaku pariwisata maupun pemerintah. Biasanya jumlah pengunjung sedikit, wisatawan tertarik pada daerah yang belum tercemar dan sepi, lokasinya sulit dicapai namun diminati oleh sejumlah kecil wisatawan yang justru menjadi berminat karena belum ramai dikunjungi.

(2).Tahap involvement yang diikuti local control biasanya oleh masyarakat lokal. Pada tahap ini ada inisiatif dari masyarakat lokal, objek wisata mulai dipromosikan oleh wisatawan, jumlah wisatawan meningkat dan infrastruktur mulai dibangun.

(3).Tahap development, dimana pada tahap ini menunjukan adanya peningkatan jumlah kunjungan wisatawan secara drastis, pengawasan oleh lembaga lokal adakala sulit membuahkan hasil, ,masuknya sendiri industri pariwisata dari luar dan kepopuleran kawasan wisata menyebabkan kerusakasn lingkungan alam dan sosial budaya sehingga diperlukan campur tangan dan kontrol penguasa lokal maupun nasional. 


\section{National Conference of Creative Industry: \\ Sustainable Tourism Industry for Economic Development}

Universitas Bunda Mulia, Jakarta, 5-6 September 2018 e-ISSN No: 2622-7436

(4).Tahap consolidation dengan constitutionalism. Pada tahap ini terjadi penurunan tingkat pertumbuhan kunjungan wisatawan. Kawasan wisata dipenuhi oleh berbagai industri pariwisata berupa hiburan dan berbagai macam atraksi wisata.

(5).Tahap stagnation yang masih diikuti institutionalism, dimana jumlah wisatawan tertinggi telah tercapai dan kawasan ini telah mulai ditinggalkan karena tidak mode lagi, kunjungan ulang dan para pebisnis manfaatkan fasilitas yang telah ada, ada upaya untuk menjaga jumlah wisatawan secara intensif dilakukan oleh industri pariwisata, dan kawasan ini kemungkinan besar mengalami masalah besar yang terkait dengan lingkungan alam maupun sosial budaya.

(6).Tahap decline, hampir semua wisatawan telah mengalihkan kunjungannya ke daerah tujuan wisata lain. Kawasan ini telah menjadi daya tarik wisata kecil yang dikunjungi sehari atau akhir pekan, beberapa fasilitas pariwisata telah dirubah fungsinya menjadi tujuan lain. Dengan demikian pada tahapan ini diperlihatkan upaya dari untuk meremajakan kembali (rejuvenate). Dimana tahapan rejuvenation perlu dilakukan pertimbangan mengubah pemanfaatan kawasan pariwisata, mencari pasar baru, membuat saluran pariwisata baru dan mereposisi atraksi wisata ke bentuk lain.

Dari pernyataan Butler diatas mengenai Tourism Life Cycle, terlihat dari trend jumlah kunjungan ke Kampung Budaya Sindangbarang dari Tahun 2008 hingga 2017 menunjukkan bahwa kondisi Kampung Budaya sudah ditahap declining. Hal ini menunjukkan bahwa Kampung Budaya Sindangbarang perlu melakukan strategi baru atau melakukan evaluasi terhadap usaha wisata yang dijalankan.

Untuk pengembangan wisata spiritual maka elemen-elemen penting yang perlu diperhatikan adalah:

(1). Elemen Atraksi

R. Conrady dan M. Buck dalam bukunya Trend and Issues in Global Tourism 2011, aktifitas wisata spiritual dikategorikan sebagai berikut:

(a). Interaction with nature \&exercise: pilgrimages, hiking, meditative, walking.

(b).With counseling: talk withpastoral worker; talk with shaman; talk with spiritual coach, etc

(c).With music: singing mantras, tones.

(d).With creativity: meditative, painting, ikebana.

(e).With physical exercises: yoga, tai chi, meditative dances, circle dances.

(f).With spiritual exercises: spiritual exercises (in silence), contemplation, meditation, trips to shamans.

(2). Elemen Tempat

Untuk klasifikasi berdasarkan tempat yang menjadi tujuan pariwisata spiritual diterangkan oleh Shackley dalam Blackwell (2007: 35-47) sebagai berikut:

(a). Natural phenomena (lakes, mountains, islands, gardens, etc.)

(b). Buildings and places that are originally made for religious purposes

(c). Buildings with religious content

(d). Special events of religious importance that are held in non religious places

(e). Places built on secular thoughts that are relevant with tragic stories or those events that are particularly political. For example, Nelson Mandela's prison on Robin island"

(3). Elemen Motivasi

Pariwisata spiritual didasari oleh dua hal seperti yang dikemukakan oleh Wilson dan Harris, dan Little dan Schmidt (2006) dalam Maulana (2014), antara lain:

(a) The "Self" 


\section{National Conference of Creative Industry: \\ Sustainable Tourism Industry for Economic Development}

Universitas Bunda Mulia, Jakarta, 5-6 September 2018 e-ISSN No: 2622-7436

Faktor the "self" atau diri yang biasanya dipergunakan untuk mencari identitas diri dan pengenalan terhadap diri biasanya mendominasi wisata jenis ini.

White $\mathrm{Li}$ at al (2006) mengemukakan bahwa hal ini didapat melalui peningkatan pendidikan dan belajar mengenai hal-hal yang baru dimana ditujukan untuk pemberdayaan diri atau individu yang bersangkutan.

(b) The "Other"

Faktor "the other" atau yang berasal dari luar diri seseorang dapat berupa budaya, lingkungan dan lainnya. Tidak akan ada self/ diri tanpa adanya other. Dengan menyadari hal tersebut maka termotivasi untuk lebih membuka hati dan memperluas pikiran guna mengikis ketegangan yang secara dinamis akan timbul dari kedua dimensi tersebut.

Pechlaner (2010) dalam Conrady (2011) mengkategorikan motivasi wisatawan melakukan perjalanan spiritual dikarenakan faktor:

(a). Agama: Pada tingkatan kebutuhan sosial menurut Maslow (1954), partisipasi pada wisata spiritual dapat memunculkan sense of belonging terhadap suatu kelompok keagamaan tertentu, khususnya yang berpaham keagamaan mendukung atau menggemari kegiatan ziarah.

(b). Budaya: Motivasi wisatawan spiritual juga disebabkan faktor budaya yang ada untuk mengenal dan memahami tata cara dan kebudayaan daerah yang dimiliki atau budaya daerah lain, seperti: kebiasaan masyarakatnya, bangunan, musik, tarian dan sebagainya sehingga timbul nilai spiritualitas dalam memahami kebudayaan yang didapat.

(c). Kesehatan: motivasi wisatawan spiritual menurut Pechlaner (2010) dalam Conrady (2011) juga untuk alasan kesehatan jiwa dan raga. Menurut Conrady (2011) saat ini wisata kesehatan termasuk dalam komponen wisata spiritual. Pada jaman dahulu ada kegiatan-kegiatan dimana tempat-tempat sumber air mineral ada yang dianggap memiliki khasiat untuk menyembuhkan penyakit atau melakukan meditasi/ yoga untuk ketenangan jiwa dan raga.

(d). Mencari arti terdalam dan mencari jati diri (Quest for a Deeper Meaning \& Identity): Menurut Maslow (1954), maka wisata spiritual setidaknya dapat menghadirkan stabilitas dan ketenangan secara psikologis dengan memelihara kesinambungan harapan, khususnya bagi yang mengalami depresi maupun keputusasaan akibat tekanan hidup.

\section{METODOLOGI PENELITIAN}

Penelitian ini bertujuan untuk mendapatkan gambaran mengenai potensi pengembangan Wisata Spiritual di Kampung Budaya Sindangbarang, Bogor. Untuk mencapai tujuan tersebut maka penelitian ini menggunakan metode deskriptif dengan pendekatan kuantitatif yaitu dengan penyebaran kuesioner ke pengunjung Kampung Budaya Sindangbarang untuk melihat potensi pengembangan wisata spiritual sebanyak. Data yang digunakan dalam penelitian ini menggunakan data primer dan sekunder. Data primer diperoleh melalui wawancara kepada petugas Kampung Budaya Sindangbarang, penyebaran kuesioner dan juga pengamatan secara langsung (Observasi). Untuk data sekunder diperoleh melalui data Dinas Pariwisata Kabupaten Bogor, Badan Pusat Statistik, dokumentasi Kampung Budaya Sindangbarang, penelitian penulis lain, instansi lain yang terkait, jurnal serta buku penunjang lain. 
National Conference of Creative Industry:

Sustainable Tourism Industry for Economic Development

Universitas Bunda Mulia, Jakarta, 5-6 September 2018

e-ISSN No: 2622-7436

VARIABEL PENELITIAN

Tabel 1

Matriks Operasional Variabel (MOV)

\begin{tabular}{|c|c|c|c|}
\hline Variabel & Dimensi & Indikator & Kriteria \\
\hline \multirow{6}{*}{$\begin{array}{l}\text { Elemen } \\
\text { Spiritual } \\
\text { Tourism } \\
\text { Pechlaner, } 2010 \\
\text { dalam Conrady } \\
(2011)\end{array}$} & \multirow{6}{*}{ Attraction } & $\begin{array}{l}\text { Wisata Spiritual Berbasis } \\
\text { Alam }\end{array}$ & $\begin{array}{lr}\text { Pengunjung } & \text { dapat } \\
\text { /tidaknya } & \\
\text { menelusuri } & \text { situs } \\
\text { sejarah dengan } \\
\text { melakukan meditasi }\end{array}$ \\
\hline & & $\begin{array}{l}\text { Wisata Spiritual Berbasis } \\
\text { Konseling }\end{array}$ & $\begin{array}{l}\text { Pengunjung dapat } \\
\text { /tidaknya } \\
\text { melakukan } \\
\text { konsultasi dengan } \\
\text { ahli spiritual seperti } \\
\text { membahas } \\
\text { permasalahan hidup, } \\
\text { baca garis tangan, } \\
\text { buka cakra dll }\end{array}$ \\
\hline & & $\begin{array}{l}\text { Wisata Spiritual Berbasis } \\
\text { Musik }\end{array}$ & $\begin{array}{l}\text { Pengunjung dapat / } \\
\text { tidaknya menikmati } \\
\text { alunan musik } \\
\text { tradisional seperti } \\
\text { tarian jaipongan }\end{array}$ \\
\hline & & $\begin{array}{l}\text { Wisata Spiritual Berbasis } \\
\text { Kreativitas }\end{array}$ & $\begin{array}{l}\text { Pengunjung dapat/ } \\
\text { tidaknya melakukan } \\
\text { pembelajaran/ } \\
\text { pengalaman melalui } \\
\text { aktifitas budaya } \\
\text { seperti melukis atau } \\
\text { membatik }\end{array}$ \\
\hline & & $\begin{array}{l}\text { Wisata Spiritual Berbasis } \\
\text { Aktifitas Fisik }\end{array}$ & $\begin{array}{l}\text { Pengunjung dapat/ } \\
\text { tidaknya menikmati } \\
\text { spiritualitas dengan } \\
\text { kegiatan yang } \\
\text { membutuhkan } \\
\text { aktifitas fisik seperti } \\
\text { melakukan tarian, } \\
\text { bermain angklung } \\
\text { gubrak, pencak silat } \\
\text { cimande, yoga dll }\end{array}$ \\
\hline & & $\begin{array}{l}\text { Wisata Spiritual Berbasis } \\
\text { Spiritual }\end{array}$ & $\begin{array}{l}\text { Pengunjung dapat } \\
\text { atau tidaknya } \\
\text { melakukan aktifitas } \\
\text { spiritual yang erat } \\
\text { kaitannya dengan } \\
\text { olah kebatinan } \\
\text { untuk menenangkan }\end{array}$ \\
\hline
\end{tabular}


National Conference of Creative Industry:

Sustainable Tourism Industry for Economic Development

Universitas Bunda Mulia, Jakarta, 5-6 September 2018

e-ISSN No: 2622-7436

\begin{tabular}{|c|c|c|}
\hline & & $\begin{array}{lr}\text { diri } & \text { atau } \\
\text { mendekatkan } & \text { diri } \\
\text { kepada Tuhan, } & \text { Teperti Meditasi, } \\
\text { Hipnoterapi (self- } \\
\text { healing dll) }\end{array}$ \\
\hline \multirow{3}{*}{ Places } & Fenomena & - Lokasi Natural \\
\hline & Konsep & $\begin{array}{llr}\text { - } & \text { Desain } & \text { lokasi } \\
\text { berbasis } & \text { budaya } \\
\text { Sunda } & \\
\end{array}$ \\
\hline & $\begin{array}{lll}\text { Relevansi } & \text { Situs dengan } \\
\text { Sejarah } & & \end{array}$ & $\begin{array}{lr}\text { - } & \text { Keaslian } \\
\text { yang ditus } & \text { ditemukan } \\
\text { sesuai dengan } \\
\text { latar belakang } \\
\text { sejarah daerah }\end{array}$ \\
\hline \multirow[t]{3}{*}{ Motives } & $\begin{array}{l}\text { Motivasi Ritual Agama/ } \\
\text { Ziarah }\end{array}$ & $\begin{array}{l}\text { Apakah pengunjung } \\
\text { dimotivasi oleh } \\
\text { agama/ aliran } \\
\text { tertentu sehingga } \\
\text { datang ke Kampung } \\
\text { Budaya } \\
\text { Sindangbarang }\end{array}$ \\
\hline & Motivasi Budaya/ Event & $\begin{array}{l}\text { Apakah pengunjung } \\
\text { dimotivasi oleh } \\
\text { budaya/ } \\
\text { tertentu sehingent } \\
\text { datang ke Kampung } \\
\text { Budaya } \\
\text { Sindangbarang }\end{array}$ \\
\hline & Menemukan Identitas Diri & $\begin{array}{l}\text { Apakah pengunjung } \\
\text { dimotivasi oleh } \\
\text { pencarian diri (agar } \\
\text { merasa tenang dan } \\
\text { tentram) sehingga } \\
\text { datang ke Kampung } \\
\text { Budaya } \\
\text { Sindangbarang }\end{array}$ \\
\hline
\end{tabular}

Sumber: Olahan Peneliti, 2017

\section{HASIL PENELITIAN DAN PEMBAHASAN}

\section{a. Lokasi dan Letak Geografis Kampung Budaya Sindangbarang}

Kampung Budaya Sindangbarang mempunyai luas tanah sebesar $8.600 \mathrm{~m}^{2}$ dan berada di kaki Gunung Salak dengan ketinggian 500 meter diatas permukaan laut dengan udaranya yang sejuk. Kampung Budaya Sindangbarang yang terletak di Desa Pasir Eurih termasuk dalam kawasan dengan iklim tropik basah dengan curah hujan rata-rata $399 \mathrm{~mm} /$ bulan dan jumlah hari hujan rata-rata 13 hari/ bulan. 


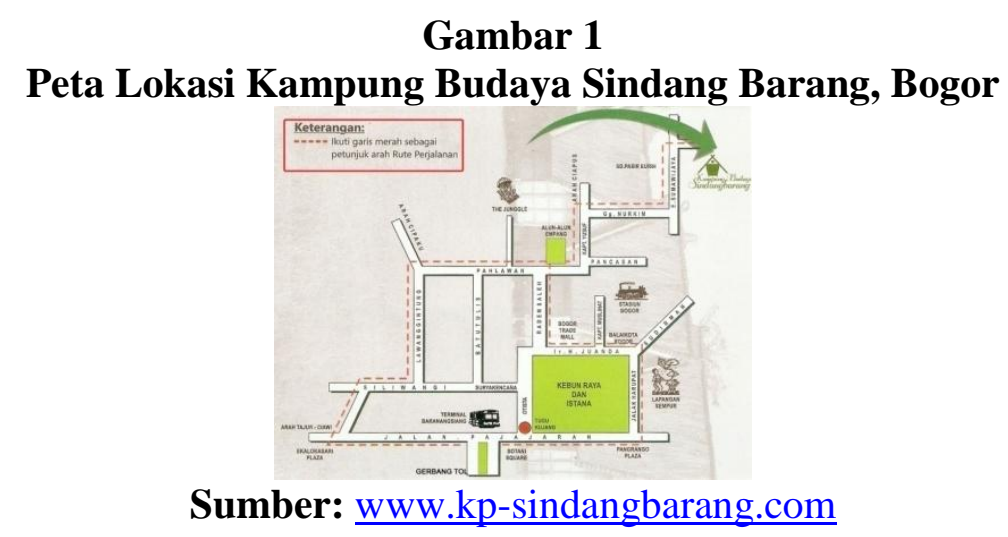

Kondisi jalan menuju Kampung Budaya Sindangbarang pada jalan utama sudah beraspal dan cukup baik karena baru saja diperbaiki pada Tahun 2016 lalu. Namun semakin mendekati lokasi, kondisi jalan memang semakin menyempit. Lebar jalan setelah melawati jalan utama hanya mampu menampung mikro bus atau bus $3 / 4$ (tiga per empat) dan itu pun memerlukan bantuan panduan dari pihak Kampung Budaya Sindang Barang untuk dapat mencapai lokasi dengan lancar. Terkadang Kampung Budaya Sindangbarang bekerjasama dengan pom bensin terdekat untuk menempatkan bus di pom bensin tersebut, untuk selanjutnya ditampung oleh beberapa angkot yang sudah di sewa untuk membawa pengunjung ke Kampung Budaya Sindangbarang. Selain mini bus, bentuk transportasi darat lainnya untuk mencapai Kampung Budaya Sindangbarang adalah dengan menggunakan sepeda motor, mobil pribadi dan juga transportasi umum.

Transportasi umum yang bisa digunakan pengunjung adalah dengan menggunakan moda transportasi darat. Rute dari Terminal Baranangsiang maupun Stasiun Bogor bisa menggunakan berbagai trayek angkot yang menuju Bogor Trade Mall (BTM), dilanjutkan dengan angkot 03 (Jurusan Ciapus-Ramayana) sampai ke Gang Nurkim. Lalu dilanjutkan ke kawasan utama dengan menggunakan ojek baik tradisional maupun online. Waktu tempuh dari BTM ke kawasan berkisar 30 menit jika lancar sampai dengan 1 (satu) jam jika terjadi kemacetan di beberapa titik. Jika menggunakan transportasi pribadi, maka rute yang bisa dilalui jika dari Terminal Baranangsiang adalah menuju ke BTM menuju Pancasan lalu Ciapus.

\section{Gambar 2}

\section{Lahan Parkir Kampung Budaya Sindangbarang Bogor}

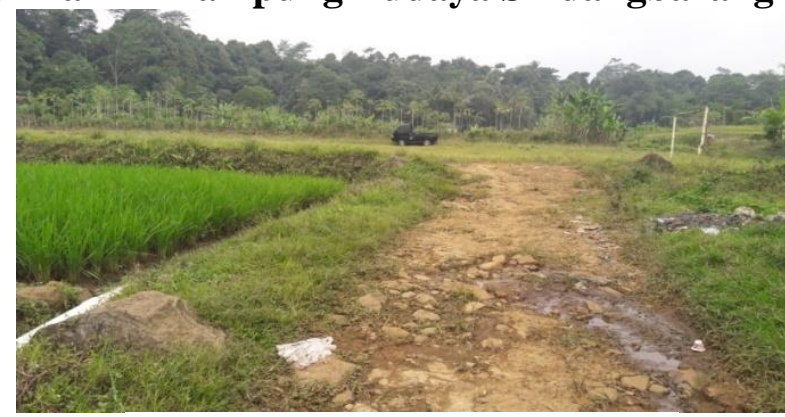

Sumber: Dokumen Pribadi, 2017

Sedangkan untuk lahan parkir sendiri tersedia lahan desa cukup luas yang bisa dipakai oleh Desa Wisata Pasir Eurih dan juga Kampung Budaya Sindangbarang. Namun memang perlu pembangunan lebih lanjut karena kondisi lahan parkirnya yang 


\section{National Conference of Creative Industry: \\ Sustainable Tourism Industry for Economic Development}

Universitas Bunda Mulia, Jakarta, 5-6 September 2018

e-ISSN No: 2622-7436

masih cukup berbatu dan cukup menyulitkan untuk masuk ke lahan parkir tersebut. Untuk akses dari lahan parkir menuju pintu masuk kawasan Kampung Budaya Sindangbarang cukup menanjak dan berbatu. Hal ini karena konsep Kampung Budaya yang bersifat alami.

\section{Gambar 3}

Akses Jalan dari Lahan Parkir menuju Pintu Masuk Kampung Budaya Sindangbarang

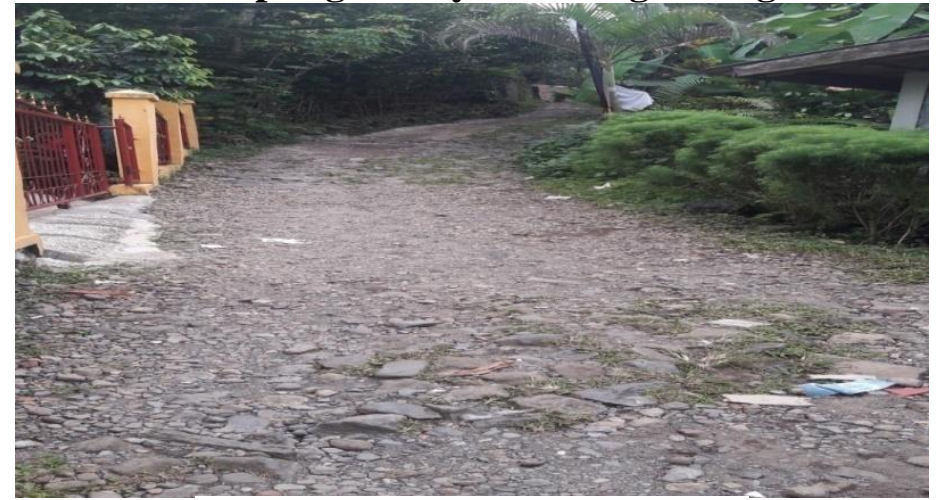

Sumber: Dokumen Pribadi, 2017

Untuk papan penunjuk informasi menuju Kampung Budaya Sindangbarang sendiri memerlukan ketelitian dari pengemudi yang baru pertama kali datang, dikarenakan papan penunjuk informasi kurang besar terutama di titik menuju Gang Nurkim yang tertutup pepohonan. Jika pengunjung tidak berhati-hati atau tidak bertanya ke masyarakat sekitar, maka pengunjung bisa tersesat.

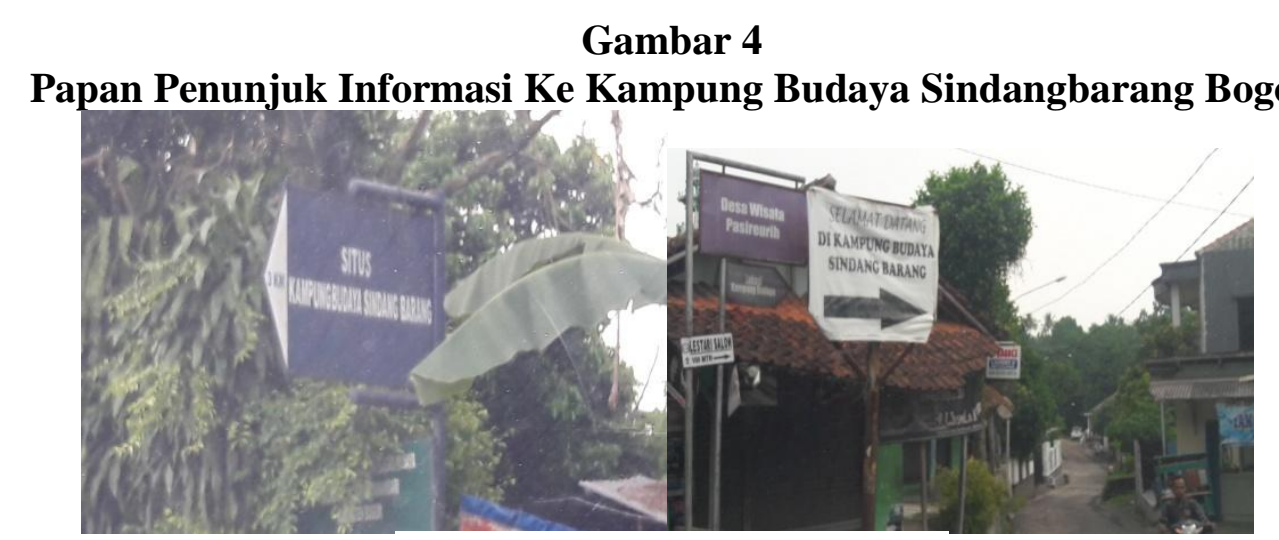

Sumber: Dokumen Pribadi, 2017

\section{b. Potensi Pengembangan Wisata Spiritual di Kampung Budaya Sindangbarang (1). Kualitas Tempat (Places)}

Berdasarkan hasil observasi didapatkan bahwa kondisi alam di sekitar Kampung Budaya Sindangbarang masih cukup asri dengan suasana pedesaan yang masih cukup kental. Selain itu desain lokasi atau bangunan berkonsep budaya Sunda Kuna juga memperkuat potensi untuk mengembangkan wisata spiritual di Kampung Budaya Sindangbarang. Hasil penelitian juga menunjukkan hal yang sama, yaitu sebagian besar responden setuju (33.33\%) dan sangat setuju (66.67\%) bahwa fenomena tempat disekitar Kampung Budaya Sindangbarang masih bersifat natural. Responden juga 
sebagian besar sangat setuju (63.33\%) bahwa lokasi atau bangunan yang berkonsep budaya Sunda Kuna berpotensi untuk dijadikan wisata spiritual. Hal ini tentu saja bisa menjadi kekuatan Kampung Budaya Sindangbarang.

\section{Tabel 2}

Sikap Pengunjung

Terhadap Kualitas Potensi Tempat (Place) Wisata Spiritual Di Kampung Budaya Sindangbarang Bogor

\begin{tabular}{|l|l|l|l|l|l|}
\hline No & Tempat & \multicolumn{4}{|l|}{ Jawaban Responden } \\
\hline & & 1 & 2 & 3 & 4 \\
\hline 1 & Lokasi Natural atau & & & $33.33 \%$ & $66.67 \%$ \\
\hline 2 & $\begin{array}{l}\text { Disain lokasi berkonsep } \\
\text { bangunan } \\
\text { budaya Sunda Kuna }\end{array}$ & & $36.67 \%$ & $63.33 \%$ \\
\hline
\end{tabular}

Keterangan Sikap: 1=Sangat tidak setuju, 2: tidak setuju, 3: setuju, 4: sangat setuju

Sumber: Data Primer Diolah, 2017

\section{(2). Ketersediaan Daya Tarik Spiritual (Attraction)}

Identifikasi potensi daya tarik wisata spiritual di Kampung Budaya Sindangbarang berdasarkan 6 (enam) kategori daya tarik wisata spiritual, yaitu potensi wisata spiritual berbasis alam, potensi wisata spiritual musik, potensi wisata spiritual berbasis konseling, potensi wisata spiritual berbasis aktifitas fisik, berbasis aktifitas fisik, dan potensi wisata spiritual aktifitas spiritual.

Tabel 3

Ketersediaan Daya Tarik (Attraction) Spiritual Di Kampung Budaya Sindangbarang Bogor

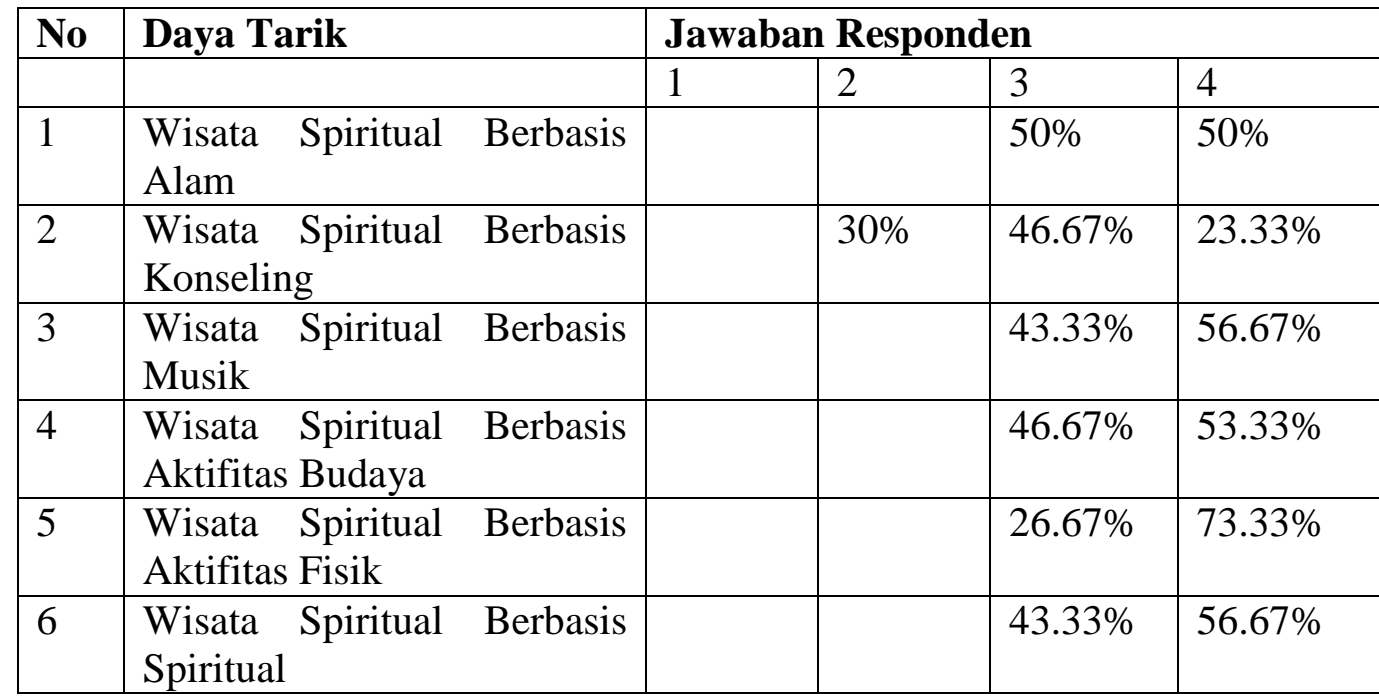

Keterangan: Sikap: 1=Sangat tidak setuju, 2: tidak setuju, 3: setuju, 4: sangat setuju

Sumber: Data Primer Diolah, 2017 


\section{National Conference of Creative Industry: \\ Sustainable Tourism Industry for Economic Development}

Universitas Bunda Mulia, Jakarta, 5-6 September 2018

e-ISSN No: 2622-7436

Berdasarkan hasil tabel diatas bisa disimpulkan bahwa sebagian besar pengunjung spiritual sangat setuju wisata spiritual berbasis aktifitas fisik yaitu sebesar 73.33\% (belajar tari, bermain angklung gubrak, bermain silat Cimande), wisata spiritual berbasis spiritual dan musik yaitu sebesar $56.67 \%$. Hal tersebut menunjukkan bahwa paket wisata seperti lagu tradisional Sunda dan juga kegiatan meditasi, yoga dan hal lainnya yang berhubungan dengan spiritual dapat lebih dikembangkan sebagai daya tarik wisata spiritual. Setengah dari pengunjung juga cukup antusias untuk melakukan wisata spiritual berbasis alam (melakukan tracking sambil berdoa) dan aktifitas budaya (membatik, melukis, dll). Hal tersebut sesuai dengan pernyataan Abah Ukat selaku Kokolot dan juga praktisi spiritual di Kampung Budaya Sindangbarang bahwa pengunjung dapat melakukan tracking dengan berdoa kepada Tuhan YME sekaligus melakukan Tafakur Alam:

“...kebanyakan pengunjung yang bukan anak sekolah, ada yang ingin melakukan meditasi di Kampung Budaya, malah ada yang sampai 2 malam. Juga ada yang ingin ke punden, atau Sumur Jalatunda, atau ke makam-makam jaman dahulu. Saya sering mengantar mereka. Sebelumnya mereka melakukan meditasi. Untuk bacaannya kalua Bergama Islam lebih ke Shalawat, namun untuk yang beragama lain seperti Hindu-Bali silahkan menggunakan doa sesuai kepercayaan masing-masing" (Wawancara Tanggal 21 Agustus 2017). Berdasarkan hasil penelitian ditemukan bahwa atraksi menjadi kekuatan Kampung Budaya Sindangbarang dalam melakukan pengembangan wisata spiritual.

\section{(3). Motivasi (Motives) Pengunjung}

Kegiatan perjalanan wisata spiritual dimotivasi oleh dorongan agama, budaya, kesehatan dan pencarian jati diri. Berikut ini hasil persepsi mengenai motivasi pengunjung spiritual yang datang ke Kampung Budaya Sindangbarang:

Tabel 4

Potensi Motivasi (Motives) Pengunjung Ke Kampung Budaya Sindangbarang Bogor

\begin{tabular}{|c|c|c|c|c|c|}
\hline No & Motivasi & \multicolumn{4}{|c|}{ Jawaban Responden } \\
\hline & & 1 & 2 & 3 & 4 \\
\hline 1 & $\begin{array}{l}\text { Motivasi Ritual Agama/ } \\
\text { Ziarah }\end{array}$ & & $3.33 \%$ & $51 \%$ & $33.33 \%$ \\
\hline 2 & Motivasi Budaya & & & $33 \%$ & $66.67 \%$ \\
\hline 3 & Motivasi Kesehatan & & $16.67 \%$ & $41.67 \%$ & $41.66 \%$ \\
\hline 4 & Motivasi Identitas Diri & $3.33 \%$ & $24.44 \%$ & $45.56 \%$ & $26.67 \%$ \\
\hline
\end{tabular}

Keterangan Sikap: 1=Sangat tidak setuju, 2: tidak setuju, 3: setuju, 4: sangat setuju

Sumber: Data Primer Diolah, 2017

Dari hasil tabel diatas terlihat bahwa motivasi terbesar pengunjung datang ke Kampung Budaya Sindangbarang adalah untuk melihat budaya (66.67\%). Hal ini dapat dipahami mengingat memang core product dari Kampung Budaya Sindangbarang sendiri adalah untuk konsep budaya. Untuk pengunjung yang tertarik oleh ajaran 


\section{National Conference of Creative Industry: \\ Sustainable Tourism Industry for Economic Development}

Universitas Bunda Mulia, Jakarta, 5-6 September 2018 e-ISSN No: 2622-7436

agama/ aliran yang dipengaruhi oleh sejarah juga terlihat lumayan besar yaitu $51 \%$ menyatakan setuju dan $33.33 \%$ menyatakan sangat setuju. Terlihat pula bahwa sebesar $41.67 \%$ dan $41.66 \%$ pengunjung setuju dan sangat setuju bahwa pengunjung datang ke Kampung Budaya ingin memulihkan dan meningkatkan kesehatan mereka. Namun terlihat pula bahwa sebesar $16.67 \%$ pengunjung tidak setuju bahwa mereka datang untuk sekedar memulihkan dan meningkatkan kesehatan. Untuk motivasi identitas diri juga terlihat bahwa hampir sebagian besar pengunjung datang ke Kampung Budaya untuk mencari ketenangan, mengupayakan terpenuhinya berbagai hajat dan keinginan bersifat duniawi, dan juga ingin mencari identitas diri. Namun juga sebagian pengunjung sebesar $3.33 \%$ dan $24.44 \%$ sangat tidak setuju dan tidak setuju bahwa motivasi mereka ke Kampung Budaya Sindangbarang untuk identitas diri.

Berdasarkan hasil jawaban responden terlihat cukup jelas bahwa motivasi pengunjung datang ke Kampung Budaya Sindangbarang cukup beragam, namun sebagian besar pengunjung setuju dan sangat setuju bahwa motivasi mereka karena tertarik oleh ajaran agama/ aliran yang dipengaruhi oleh sejarah, budaya Sunda, alasan kesehatan, dan juga untuk identitas diri. Hal tersebut menunjukkan bahwa terdapat potensi lain yang bisa dikembangkan oleh Kampung Budaya Sindangbarang untuk memperkaya produk utama wisatanya.

\section{KESIMPULAN}

Berdasarkan hasil penelitian dan pembahasannya, dapat disimpulkan bahwa:

1. Kampung Budaya Sindangbarang merupakan salah satu destinasi pariwisata di Kabupaten Bogor yang berada di Desa Pasir Eurih, Kabupaten Bogor yang berdiri sejak Tahun 2007. Kampung Budaya Sindangbarang dibentuk dilatarbelakangi oleh upaya pengembangan dan pelestarian kebudayaan Sunda yang hampir punah sehingga tidak hilang dan bisa menjadi warisan generasi mendatang.

2. Kampung Budaya Sindangbarang memiliki keadaan alam yang cukup baik karena berada di kaki Gunung Salak. Suasana pedesaan dapat dirasakan karena di sekitar Kampung Budaya Sindangbarang terdapat hamparan persawahan yang cukup luas, sungai yang mengalir jernih dan juga masyarakat sekitar yang cukup bersahabat. Berdasarkan latar belakang sejarah yaitu berdasarkan Babad Pajajaran dan Pantun Bogor, dinyatakan bahwa wilayah Kampung Sindangbarang berasal dari masyarakat Sunda Kuna disekitar abad ke-15 M hingga keruntuhannya. Ditemukan juga berbagai situs sejarah disekitar Kampung Budaya seperti menhir, dolmen, punden berundak, sumur Jalatunda dan Taman Sri Bagenda. Berdasarkan hal tersebut maka Kampung Budaya Sindangbarang berpotensi untk menambah paket wisata baru yang lebih kearah spiritualitas untuk memperkaya produk wisata selain budaya dan sejarah.

3. Variabel yang dipakai untuk melihat potensi pengembangan wisata spiritual menggunakan teori Elemen Spiritual (Pechlaner, 2010 dalam Conrady, 2011) dengan dimensi attraction, places dan motives.

4. Berdasarkan hasil analisis didapatkan temuan bahwa elemen spiritual tourism berupa attraction, places dan motives dapat menjadi kekuatan Kampung Budaya Sindangbarang dalam mengembangkan wisata spiritual.

\section{SARAN}




\section{National Conference of Creative Industry: \\ Sustainable Tourism Industry for Economic Development}

Universitas Bunda Mulia, Jakarta, 5-6 September 2018

e-ISSN No: 2622-7436

Berdasarkan hasil penelitian Dalam melakukan pengembangan wisata Kampung Budaya Sindangbarang maka dapat memasukkan unsur wisata spiritual sebagai added value dari pengembangan wisata budaya dan sejarah yang sudah diterapkan oleh Kampung Budaya Sindangbarang selama hampir 10 tahun kebelakang. Diharapkan pihak pengelola memiliki rencana jangka pendek maupun jangka panjang untuk berinovasi dalam melakukan pengembangan wisata lain untuk terus meningkatkan kunjungan wisatawan kedepannya.

\section{DAFTAR PUSTAKA}

Berkemann, K. 2006. Spiritueller Tourismus in Sachsen-Anhalt. Ergebnisse einer landesweiten Studie. In: Ministerium für Wirtschaft und Arbeit Sachsen-Anhalt (ed.) Heilige Orte, sakrale Räume, Pilgerwege. Möglichkeiten und Grenzen des spirituellen Tourismus. Tourismus-Studien Sachsen-Anhalt, pp. 36-45. Magdeburg, Lutherstadt Wittenberg, Bensberg.

Blackwell, R. 2007. Motivations for Religious Tourism, Pilgrimage, Festivals and Events in R.Raj and N. Morpeth, Religious Tourism and Pilgrimage Festivals Management: An International Perspective. Wallingford, UK: CABI Publishing.

Brämer, R. 2009. Heile Welt zu Fuß. Pilgerstudie 2009. Melalui <www.wanderforschung.de/files/pilgern0921264775103.ppt> (8/17/10)

Conrady, Roland \& Martin Buck. 2011. Trends and Issues in Global Tourism 2011, In Collaboration with Pia Viehl and Kartin Tittle. Springer-Verlag Berlin Heidelberg. Germany.

Freyer, W. 2009. Tourismus: Einführung in die Fremdenverkehrsökonomie, 9th ed. Oldenbourg, Munich.

Herdina, Lintang.Wisata Spiritual, Perjalanan Suci Peziarah Urban. Melalui <http://www.kompasiana.com/linherdina/wisata-spiritual-perjalanan-sucipeziarah-urban_55185752a333117f07b6644a > . (15/10/12).

JIBI. Meraba Wisata Spiritual Sebagai Roh Pariwisata Indonesia. Melalui http://semarang.bisnis.com/read/20170321/20/92875/meraba-wisata-spiritualsebagai-roh-pariwisata-indonesia- $(21 / 03 / 17)$

Maslow, Abraham H. 1954. Motivation And Personality. Harper \& Row Publiser, New York

Maulana, Addin. 2014. Strategi Pengembangan Wisata Spiritual di Kabupaten Badung, Provinsi Bali. Jurnal Kepariwisataan Indonesia. Vol. 9 No. 2 Juni 2014 ISSN $1907-9419$

Munandar, Agus Aris. 2007. Situs Sindangbarang Bukti Kegiatan Keagamaan Masyarakat Kerajaan Sunda (Abad 13-15M), Laporan Hasil Penelitian Awal. Bogor: Padepokan Giri Sunda Pura

Pendit, Nyoman S, 1999. Ilmu Pariwisata Sebuah Pengantar Perdana. PT.Pradnya Paramita. Jakarta.

Pitana, I Gde. Keynote Speaker Seminar Spiritual Tourism. Bali Hai Room-Inna Grand Bali Beach Hotel, Sanur Bali. Melalui http://bali.antaranews.com/berita/25650/Spiritual-tourism-menuju-wisataberkualitas

Ridwan. 2012. Perencanaan dan Pengembangan Pariwisata. Jakarta: PT. Soft Media. 


\section{National Conference of Creative Industry: \\ Sustainable Tourism Industry for Economic Development}

Universitas Bunda Mulia, Jakarta, 5-6 September 2018 e-ISSN No: 2622-7436

Smith, M. \& Kelly, C. (2006). Holistic tourism- journeys of the self. Tourism Recreation Research. 31(1)

Sukardi, Nyoman. 1998. Pengantar Pariwisata. STP Nusa Dua Bali.

Swarbrooke, John. 2012. The Development and Management of Visitor Atrraction. 2nd Ed. Butterworth-Heinemann.

Sukidi. 2001. New Age wisata Spiritual Lintas Agama. Jakarta: Gramedia Pustaka Utama.

Yoeti, Oka A.1996. Pariwisata Berbasis Budaya, Masalah dan Solusinya. Jakarta: PT.Pradnya Paramita. 